\title{
Striate palmoplantar keratoderma
}

INSERM

\section{Source}

INSERM. (1999). Orphanet: an online rare disease and orphan drug data base. Striate palmoplantar keratoderma. ORPHA:50942

Striate palmoplantar keratoderma is an isolated, focal, hereditary palmoplantar keratoderma characterized by linear hyperkeratosis along the flexor aspect of the fingers and on palms, as well as focal hyperkeratosis of the plantar skin. Patients present with painful thickening of the skin on palms and soles, with occasional fissuring, blistering and hyperhidrosis. Rarely, hyperkeratosis on other areas may be seen (knees, dorsal aspects of the digits). Histopatologically, widened intercellular spaces between keratinocytes are observed. 